\title{
Synthesis of MCM-48 with a high thermal and hydro-thermal stability
}

\author{
Wei Zhao * Zhengping Hao, Chun $\mathrm{Hu}$ \\ Research Center for Eco-Environmental Sciences, Chinese Academy of Sciences, Beijing 100085, PR China
}

Received 29 June 2004; received in revised form 18 April 2005; accepted 17 May 2005

\begin{abstract}
High thermal and hydro-thermal stable MCM-48 was synthesized by a mixed nonionic-cationic surfactant templating pathway. The sample retains its cubic structure when at $1000{ }^{\circ} \mathrm{C}$ for $2 \mathrm{~h}$ and when calcined in air with $100 \%$ water vapor at $600{ }^{\circ} \mathrm{C}$ for $2 \mathrm{~h}$.

(C) 2005 Elsevier Ltd. All rights reserved.
\end{abstract}

\section{Introduction}

Recently, mesoporous molecular sieves designated M41s have attracted much attention because of their possible uses as supports for catalysts, a host for nanosize materials, and other applications such as in chromatographic separation and membrane-based gas separation [1-3]. MCM-48, one member of these new materials contains two independent three-dimensional pore systems, which are interwoven and situated in a mirror-plane position to each other [4]. This special pore system provides favorable mass transfer kinetics in catalytic and separation applications than MCM-41 with a one-dimensional hexagonal directional pore system. However, both the critical synthesis condition and the disappointing hydro-thermal stability restrained the advantage of MCM-48 greatly. Although there are some reports of the improvement of the hydro-thermal stability of MCM-48 [5,6], but these methods make the synthesis procedure more complex and only study the hydro-thermal stability of MCM-48 in boiling water. In this paper, we introduced a simple and convenient method to synthesize the high quality MCM-48 and studied the thermal and hydro-thermal stability of this sample under the condition near to the industrial

\footnotetext{
* Corresponding author.

E-mail address: zhaowei@mail.rcees.ac.cn (W. Zhao).
} 
application. It is noted that the obtained MCM-48 sample can retain its cubic mesoporous structure even after calcination in air at $1000{ }^{\circ} \mathrm{C}$ for $2 \mathrm{~h}$. This result has not been reported.

\section{Experimental}

A typical synthetic procedure is as follows: the aqueous solution of water glass $\left(\mathrm{Na}_{2} \mathrm{O}: 7.4 \%, \mathrm{SiO}_{2}\right.$ : $25.4 \%$ ) was drop wise added under constant stirring to the mixed solution of poly(ethyleneglycol) isooctylphenyl ether (Tx-100) and cethyltrimethylammonium bromide (CTAB). This solution was then stirred at $30{ }^{\circ} \mathrm{C}$ for $1 \mathrm{~h}$. The molar composition of the resultant mixture was $1.0 \mathrm{SiO}_{2}: x \mathrm{CTAB}: y \mathrm{Tx}-$ 100:0.282 $\mathrm{Na}_{2} \mathrm{O}: 58 \mathrm{H}_{2} \mathrm{O}$, where $0.12<x<0.16,0.02<y<0.04$ (the molar composition of the blank test is similar to this except leaving off the Tx-100). After that, this mixture was placed in a static autoclave at $100{ }^{\circ} \mathrm{C}$ for 2 days. The product was recovered by filtration, washed with distilled water and dried at $80{ }^{\circ} \mathrm{C}$. At last, this material was calcined in air at $650{ }^{\circ} \mathrm{C}$ for $5 \mathrm{~h}$ followed by in air at $800{ }^{\circ} \mathrm{C}$ for another short time (designated as MCM-48 (o)). For the thermal and hydro-thermal stability studies, $0.5 \mathrm{~g}$ MCM-48 (o) was calcined in air at $1000{ }^{\circ} \mathrm{C}$ for $2 \mathrm{~h}$ (designated as MCM-48 (t)) or in air with 100\% water steam at $600{ }^{\circ} \mathrm{C}$ for $2 \mathrm{~h}$ (designated as MCM-48 (h)) in a quartz tube.

\section{Results and discussion}

The powder X-ray diffraction patterns of the resultant materials corresponded well to those reported for purely siliceous MCM-48 [7]. As shown in Fig. 1, the (420), (332) diffraction line are well resolved in the case of MCM-48 (o) sample. In the TEM image of this sample (Fig. 2), the channel like appearance in the $\left[\begin{array}{lll}1 & 1 & 0\end{array}\right]$ direction looks very orderly. These facts indicate that MCM-48 (o) has excellent textural uniformity. Both MCM-48 (t) and MCM-48 (h) still exhibited two obvious peaks (2 111 and 2220$)$ at

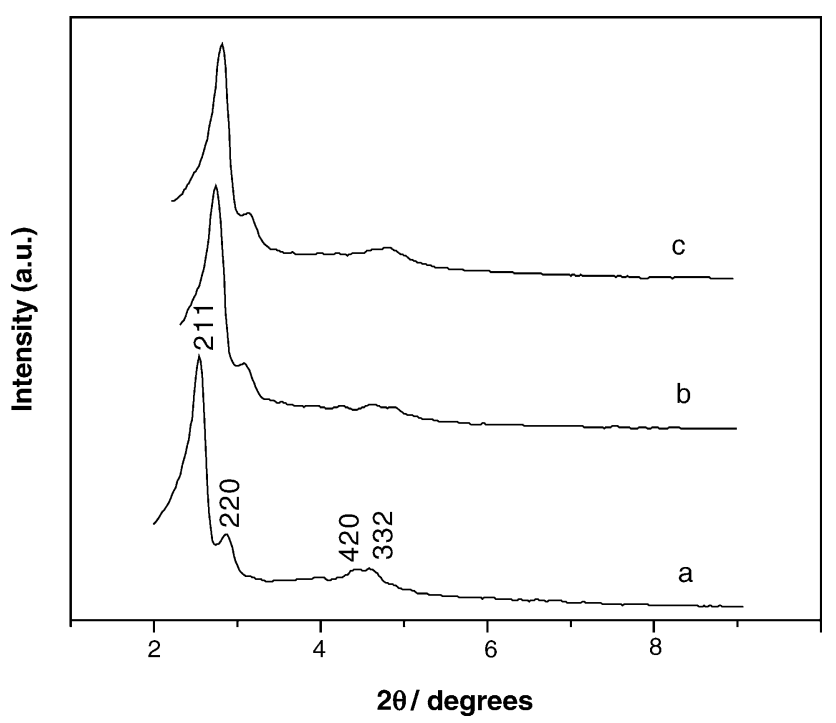

Fig. 1. XRD patterns of (a) MCM-48 (o), (b) MCM-48 (h), and (c) MCM-48 (t). 


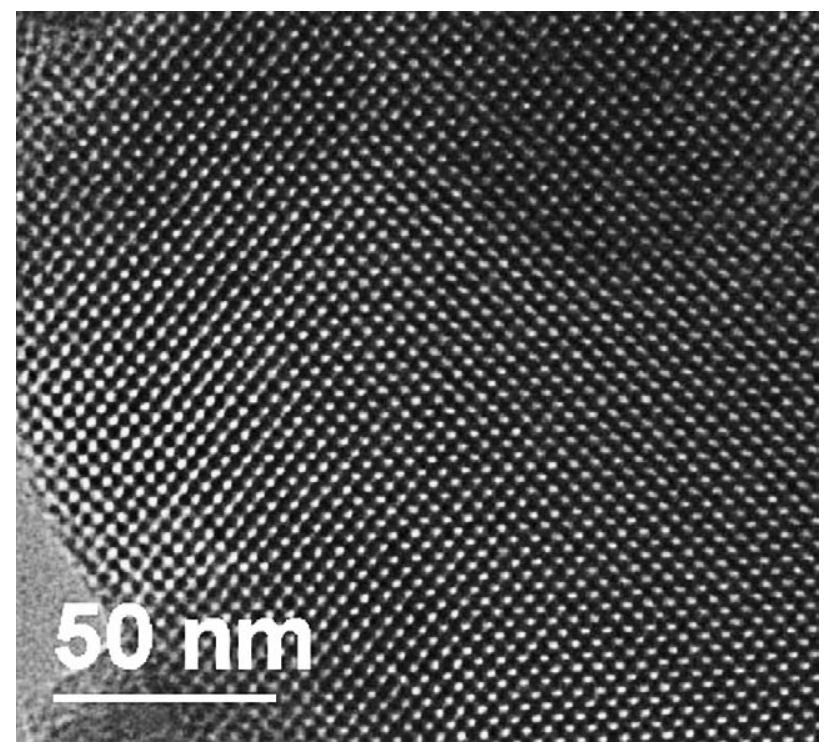

Fig. 2. HRTEM image of MCM-48 (o) on the (1 110$)$ cubic plane.

$d=31.9,28.5 \AA$ and two weak peaks (420 and 332) at $d=18.0,17.3 \AA$. It means that these two samples also keep the textural uniformity of cubic (Ia3d) structure even following the critical disposal of thermal and hydro-thermal, although the long-range structure order of them are somewhat decreased. All of above show that the textural uniformity, thermal stability and hydro-thermal stability of MCM-48 have been improved markedly by the improved synthesis route of mixed cationic and nonionic surfactant and the novel calcinations method.

The $\mathrm{N}_{2}$ adsorption-desorption isotherms and the corresponding BJH pore size distributions based on the desorption branch for the MCM-48 samples are shown in Fig. 4. All of the isotherms are typical irreversible IV adsorption isotherm with two separate $\mathrm{H} 1$ and $\mathrm{H} 4$ hysteresis loops as defined by IUPAC [8]. The first well-defined step in the adsorption curve between partial $p / p_{0}$ of 0.2 and 0.35 is indicative of the filling of framework-confined mesoporous. The second condensation step on the isotherm between $p /$ $p_{0}=0.4$ and 1.0 exhibits a substantial hysteresis loop which may be due to the inter particle capillary condensation. Both $\mathrm{H} 1$ hysteresis loops of the disposed MCM-48 samples shift toward low $p / p_{0}$ slightly. And among them, the hysteresis loop of the MCM-48 (t) not only shifts further toward low $p / p_{0}$, but also looked smoother than that of the MCM-48 (h). It suggests the pore structure of MCM-48 (t) was damaged more seriously than that of MCM-48 (h), although their X-ray diffraction patterns are similar. This is in good agreement with the TEM results (Fig. 3) and the distribution of pore diameter of these two samples (Table 1). In the wide range, both the TEM images of MCM-48 (t) and MCM-48 (h) keep their order of the channel, so their X-ray diffraction patterns are similar. While in the narrow range, some pores of MCM-48 (t) are damaged more seriously than that of MCM-48 (h) (arrow shows in Fig. 3). As a result, the FWHM of MCM-48 (t) is wider than that of MCM-48 (h), while the BET and pore volume of MCM48 (t) decrease sharply. In addition, the H4 hysteresis loop of MCM-48 (t) (Fig. 4) is larger than that of the MCM-48 (h). This suggests that the large inter-particle pores of MCM-48 (t) may be damaged. This change may also partly contribute to the decrease of BET and pore volume of MCM-48 (t) sample. 

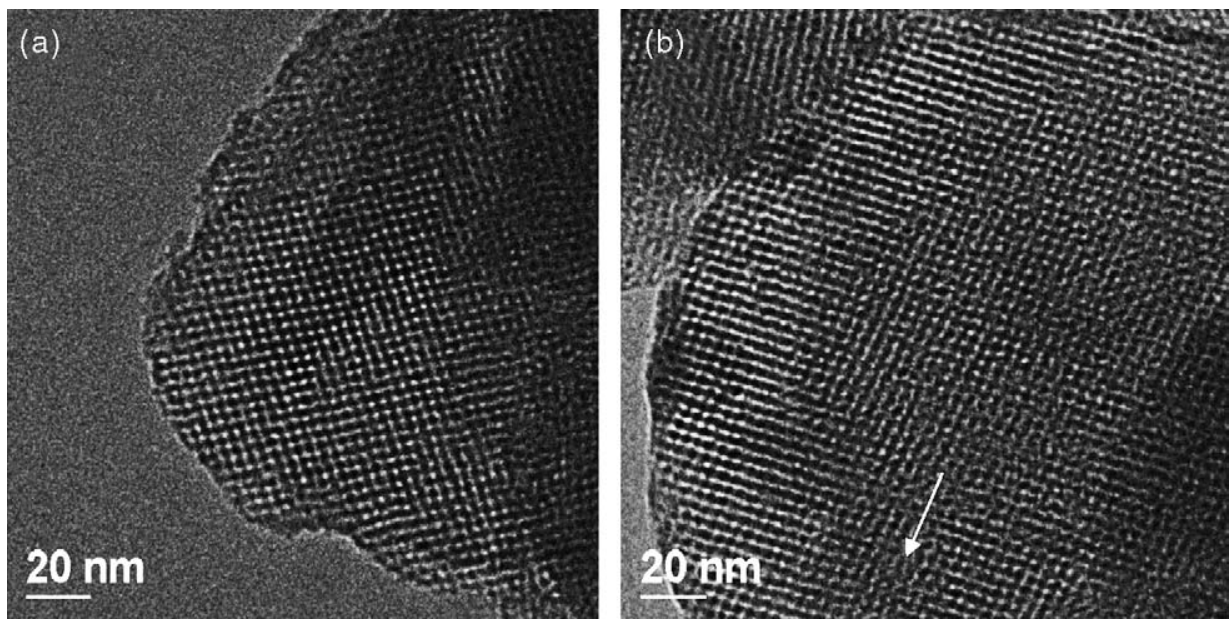

Fig. 3. HRTEM image of MCM-48 (h) (a) and MCM-48 (t) (b) on the (1 110$)$ cubic plane.

The excellent hydro-thermal and thermal stability of the obtained MCM-48 sample may be due to three factors: (1) the amount of $\mathrm{CTA}^{+}$cationic is much lower in the mother liquor $\left(\mathrm{CTAB} / \mathrm{SiO}_{2}=0.15\right)$, so, the number of compensation anionic (the silicate species) will decrease in order to keep the electric charge balance. Then, the rearrangement and polymerization of the silicate species themselves proceed further. As a result, the formation of highly connected silicate polyanions is achieved (the ratio of $Q^{4} / Q^{3}$ is 3.31, where $Q^{4}$ corresponds to the $\mathrm{Si}(\mathrm{SiO})_{4}$ units; $Q^{3}$ corresponds to the $(\mathrm{SiO})_{3}-\mathrm{SiOH}$ units). (2) As a small amount of Tx-100 in the as-synthesized MCM-48 is advantageous for the Hoffman elimination and combustion of CTAB at low temperature (see next discussion); so, upon calcination, the defects of the structure, which seem to induce the collapse of the framework at high temperature and easy to be attacked by water molecules in hot water, will decrease. Fig. 5 is the DTG spectra of the as-synthesized MCM-48 (bottom) and the blank sample (top). For the spectra of as-synthesized MCM-48, the peak b can be assigned to the Hoffmann elimination (giving $\mathrm{C}_{16} \mathrm{H}_{32}$ and $\left(\mathrm{CH}_{3}\right)_{3} \mathrm{~N}$ ) and subsequent trimethylamine desorption; the peak c can be assigned to the desorption and subsequent oxidization of hexadecane and its decomposition products; and the peak d probably can be assigned to the water loss relating to the Tx-100 and the condensation of silanol group. Compared to the blank sample (without Tx-100), both the peak $\mathrm{b}$

Table 1

Physical characteristics of MCM-48 samples under investigation

\begin{tabular}{llllll}
\hline Sample & $\begin{array}{l}\text { Unit cell } \\
\text { parameter }(\AA)^{\mathrm{b}}\end{array}$ & $\begin{array}{l}\text { BET surface } \\
\text { area }\left(\mathrm{m}^{2} \mathrm{~g}^{-1}\right)\end{array}$ & $\begin{array}{l}\text { Pore volume } \\
\left(\mathrm{cm}^{3} \mathrm{~g}^{-1}\right)\end{array}$ & Pore size $(\AA)$ & FWHM $(\AA)^{\mathrm{c}}$ \\
\hline MCM-48 $^{\mathrm{a}}$ & 83.1 & & 1.40 & 24.3 & 5.1 \\
MCM-48 (o) & 82.8 & 1148.7 & 1.37 & 23.5 & 3.5 \\
MCM-48 (h) & $78.3(5.4 \%)$ & 1037.8 & 1.16 & 21.2 & 4.7 \\
MCM-48 (t) & $78.3(5.4 \%)$ & 762.8 & 0.68 & 20.9 & 5.3 \\
\hline
\end{tabular}

\footnotetext{
${ }^{\text {a }}$ MCM-48 sample that can only be calcined in air at $650{ }^{\circ} \mathrm{C}$ for $5 \mathrm{~h}$.

b The values in parentheses are the lattice contraction upon disposal with respect to the MCM-48 (o).

c The full-widths at half-maximum for the pore size distribution curves.
} 


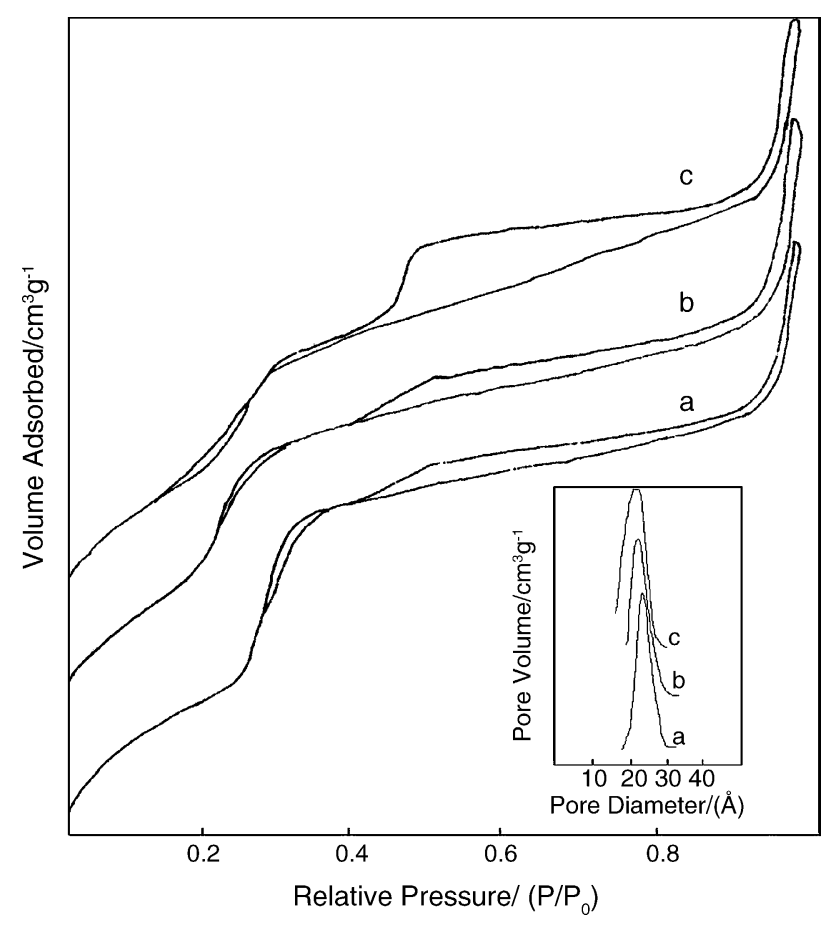

Fig. 4. $\mathrm{N}_{2}$ adsorption-desorption isotherms and pore size distribution of (a) MCM-48 (o), (b) MCM-48 (h), and (c) MCM-48 (t).

and $\mathrm{c}$ of the as-synthesized MCM-48 shift toward the low temperature region. This can be explained as follows: the hydrogen bond between the $\mathrm{CTA}^{+}$and $\mathrm{Tx}-100$ can weaken the static interaction between $\mathrm{CTA}^{+}$and the initially solidified mesoporous silica wall with the negative charge, and then cause the thermal desorption or decomposition of $\mathrm{CTA}^{+}$easily. Further, the $\mathrm{O}$ atom of Tx-100 can decrease the formation of coke, and then, favor the burning off the decomposition products of $\mathrm{CTA}^{+}$at low temperature. 3. Since the FWHM of MCM-48* (sample only calcined in air at $650{ }^{\circ} \mathrm{C}$ for $5 \mathrm{~h}$, see Table 1) is $5.1 \AA$ which is $1.6 \AA$ wider than that of MCM-48 (o), we believe that the calcination procedure

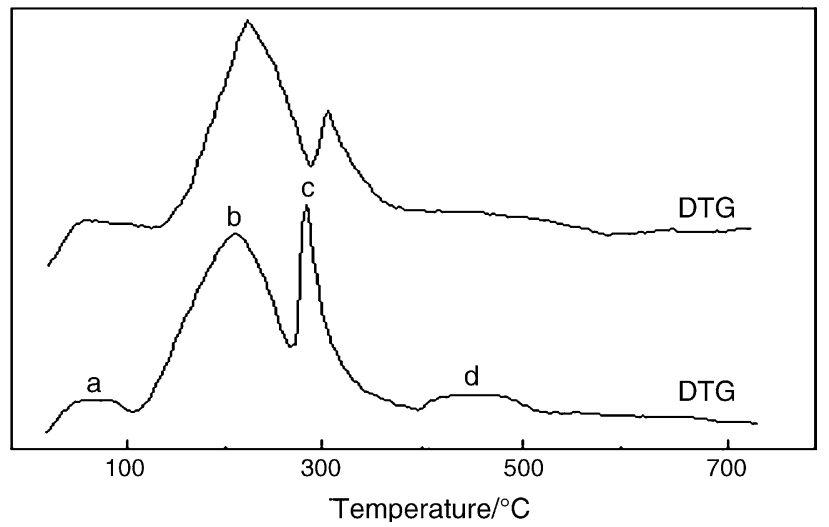

Fig. 5. DTG spectra of the as-synthesized MCM-48 (bottom) and the blank sample (top). 
at $800{ }^{\circ} \mathrm{C}$ probably can cause a local reconstruction process of the framework which can optimize the pore structure of MCM-48.

\section{Acknowledgements}

The authors wish to acknowledge financial support from the key project of knowledge innovation of the Chinese Academy of Sciences (KICX3-SW-430) and the project of the Chinese Natural Science Foundation (20322201).

\section{References}

[1] R. Ryoo, S. Jun, J. Phys. Chem. B 101 (1997) 317.

[2] X.S. Zhao, G.Q. Lu, A.K. Whittaker, G.J. Millar, H.Y. Zhu, J. Phys. Chem. B 101 (1997) 6525.

[3] K. Moller, T. Bein, Chem. Mater. 10 (1998) 2950.

[4] H. Kosslick, G. Lischke, H. Landmesser, B. Parlitz, W. Storek, R. Fricke, J. Catal. 176 (1998) 102.

[5] J. Xu, Z. Luan, H. He, W. Zhou, L. Kevan, Chem. Mater. 10 (1998) 3690.

[6] R. Ryoo, S.H. Joo, J.M. Kim, J. Phys. Chem. B 103 (1999) 7435.

[7] F. Chen, L. Huang, Q. Li, Chem. Mater. 9 (1997) 2685.

[8] K.S.W. Sing, D.H. Everett, R.A.W. Haul, L. Moscon, R.A. Pierotti, J. Rouquerol, T. Siemieniewska, Pure Appl. Chem. 57 (1985) 603. 